\title{
mTOR inhibitor Everolimus-induced apoptosis in melanoma cells
}

\author{
Dorota Ciołczyk-Wierzbicka $^{1}$ (i) $\cdot$ Marta Zarzycka ${ }^{1} \cdot$ Dorota Gil $^{1} \cdot$ Piotr Laidler $^{1}$
}

Received: 2 February 2019 / Accepted: 22 February 2019 / Published online: 8 March 2019

(C) The Author(s) 2019

\begin{abstract}
Melanoma is the most aggressive, therapy-resistant skin cancer. The mammalian target of rapamycin (mTOR), the serine/ threonine kinase which integrates both intracellular and extracellular signals, plays a crucial role in coordinating the balance between the growth and death of cells. The object of this study is a comparison of the influence of mTOR inhibitor everolimus in the concentration range between $20 \mathrm{nM}$ and $10 \mu \mathrm{M}$, used individually and in combination with selected downstream protein kinases inhibitors: LY294002 (PI3K), U0126 (ERK1/2), AS-703026 (MEK) and MK-2206 (AKT) on the expression of prosurvival proteins: p-Bcl-2 (S70), p-Bcl-2 (T56), Bcl-2, Bcl-xL, Mcl-1, activity of caspase-3, proliferation and induction of apoptosis in melanoma cells. Current results clearly show that the nanomolar concentration of the mTOR inhibitor everolimus in combination with the inhibitor of MAP kinase (AS-703026) or AKT kinase (MK-2206) is effective in inducing apoptosis and reducing proliferation of melanoma cells. The herein research results confirm the hypothesis on the important role of mTOR signaling in cancer progression, and gives hope that implementation of successful combination of its inhibitors will find recognition and application in cancer treatment in the near future.
\end{abstract}

Keywords Melanoma $\cdot$ Apoptosis $\cdot$ Caspase-3 activity $\cdot$ Proliferation $\cdot$ Protein kinase inhibitors $\cdot$ mTOR

\section{Introduction}

Apoptosis, or programmed cell death, plays an important role in controlling number of cells in many developmental and physiological processes and in oncotherapy-induced killing of cancer cells (Galluzzi et al. 2018). It is a structured, genetically regulated biological process guided by the ratio of pro-apoptotic and anti-apoptotic proteins (Hu and Kavanagh 2003).

In particular anticancer therapies, it is important to understand the mechanisms associated with cell death as it is believed that besides inhibition of tumour growth and cell invasion, the effectiveness of anticancer therapy depends mainly on its ability to induce apoptosis in cancer cells (Pfeffer and Singh 2018).

The mTOR protein is a serine/threonine protein kinase consisting of two complexes: mTORC1 and mTORC2. The mTORC1 complex activates two best characterized downstream effectors: S6 ribosomal kinase1 (S6K1) and eukaryotic

Dorota Ciołczyk-Wierzbicka

mbciolcz@cyf-kr.edu.pl

1 Medical Biochemistry, Jagiellonian University Medical College, ul. Kopernika 7, 31-034 Kraków, Poland initiation factor 4E-binding protein 1 (4E-BP1), and initiates translation of key proteins for regulation of metabolism and processes that are fundamental to cell growth, proliferation, cell cycle and autophagy (Watanabe et al. 2011; Paquette et al. 2018). It seems that the basic function of the TORC 2 complex is cytoskeletal organization and regulation of cell survival and invasion (Kim et al. 2017).

Dysregulation or stimulation of PI3K-AKT and mTOR pathway plays a significant role in oncogenesis (Yang et al. 2017; Li et al. 2018). Overexpression of proteins of this pathway, and intensified intracellular signal transduction have been confirmed in numerous types of cancer including breast, ovarian, prostate, gastric, kidney, bladder, melanoma, hepatocellular carcinoma (Kim et al. 2017; Ruzzolini et al. 2017; Conciatori et al. 2018), and tumours of hematological origin, such as acute leukemia, mantle cell lymphoma, Hodgkin's disease or multiple myeloma (Barrett et al. 2012).

Large-scale randomized trials have demonstrated that everolimus prolongs survival of patients with solid cancers, such as advanced breast cancer, renal cell carcinoma, and several kinds of neuroendocrine tumour (Lin et al. 2016; Kim et al. 2017; Li et al. 2018). Literature data Weeber et al. (2017) also suggest that the benefits of everolimus-based therapy depend on the genetic status of mutations in B-RAF and Phosphatase and Tensin Homolog (PTEN). The loss of 
function or aberration of PTEN is associated with the success of treatment, while B-RAF wild type could be responsible for the resistance. PTEN status may potentially affect the choice of clinical treatment and require reduced agent doses, thereby reducing toxicity in combined inhibition of the MEK/ERK, PI3K/AKT and mTOR pathways (Sathe et al. 2018). Limited anti-tumour effects of mTOR inhibitors (rapalogs), may be related to the induction of signaling feedback loops (Conciatori et al. 2018; Sathe et al. 2018]. In view of the above, the simultaneous blocking of both signaling pathways - PI3K/AKT and mTOR - can be an effective therapeutic strategy on account of promoting prolonged AKT, S6K1 and 4E-BP1 dephosphorylation and induction of apoptosis (Conciatori et al. 2018; Sathe and Nawroth 2018).

Literature data (Kim et al. 2017) and our own results (Ciołczyk-Wierzbicka and Laidler 2018; CiołczykWierzbicka et al. 2018) suggest that mTOR inhibitors - both rapamycin and everolimus - have significant impact on cell cycle regulation, reduction of cell proliferation and invasiveness of melanoma cells (Ciołczyk-Wierzbicka and Laidler 2018; Ciołczyk-Wierzbicka et al. 2018). They also inhibit expression of anti-apoptotic protein as well as induce apoptosis and autophagy (Kim et al. 2017).

Since many current studies searching for effective anticancer treatment focus their efforts on new capabilities of the already registered drugs and their use in combination with other potential ones, the herein study focuses on the effects of protein kinase inhibitors, and in particular the very promising mTOR inhibitor everolimus, on expression of pro-survival Bcl-2 family proteins, caspase-3 activity, and induction of apoptosis in melanoma cells.

\section{Materials and methods}

\section{Cell culture}

Human melanoma cell lines: primary WM115 (VGP) and metastatic: WM266-4 (derived from metastatic site - right thigh skin). These cells lines feature the specific V600D mutation in the B-RAF gene, as well as express PTEN loss of function including hemizygous deletion and wild type for $\mathrm{N}$ ras, c-KIT and CDK4. Cells were cultured in RPMI-1640 medium supplemented with $10 \%$ fetal bovine serum and antibiotics: penicillin and streptomycin. Cells were incubated at $37^{\circ} \mathrm{C}$ in a humidified atmosphere of $5 \% \mathrm{CO}_{2}$ in air. Cells were treated with inhibitors of: 1/AKT - MK-2206 (Selleck) at $2 \mu \mathrm{M}$ concentration, 2/ MEK - AS-703026 (Selleck) at $10 \mu \mathrm{M}$ concentration, 3/ PI3K - LY294002 (Cell Signalling TM) at $20 \mu \mathrm{M}$ concentration, 4/ ERK1/2 - U0126 (Cell Signalling TM) at $10 \mu \mathrm{M}$ concentration, and 5/ mTOR everolimus (Selleck) at: $20 \mathrm{nM}, 2 \mu \mathrm{M}, 5 \mu \mathrm{M}$ and $10 \mu \mathrm{M}$ concentrations. The incubation time of melanoma cells with inhibitors were 24 and $48 \mathrm{~h}$. Cells were obtained from the ESTDAB Melanoma Cell Bank (Tubingen, Germany).

\section{Caspase-3 activation assay}

Activation of caspase- 3 in response to applied inhibitors was estimated by means of fluorogenic substrate DEVD-AFC (Biovision). The cells were seeded in 24-well plates $\left(5 * 10^{4}\right.$ cell/well). After $24 \mathrm{~h}$ growth period, they were treated with individual selected inhibitors or their combinations, as well as with vehicle (DMSO) as control. After respective incubation time, the cells were lysed in lysis buffer $(50-\mathrm{mM}$ Tris- $\mathrm{HCl}$, $\mathrm{pH}$ 7.6, 100-mM NaCl, 1-mM EDTA, $1 \%$ Triton X-100) and incubated (1,5 h; RT) with fluorogenic substrate $(20 \mathrm{mmol} / \mathrm{l}$ Ac-DEVD-AFC). To stop the reaction, the inhibitor of caspase-3 activity (200 nM/1 DEVD-CHO) was added, and the amount of AFC released during incubation was measured by means of spectrofluorometer (Hitachi-2000; $\lambda$ ex $=400 \mathrm{~nm}$ and $\lambda \mathrm{em}=505 \mathrm{~nm}$ ). The signal corresponding to the caspase- 3 activity was normalized to the cell number (determined using the violet crystal test) and reported as fold increase of DEVDlike caspase- 3 activity in relation to control sample.

\section{DNA fragmentation ELISA assay}

Apoptosis induction was verified by assessment of the intracellular level of cytoplasmic histone-associatedDNA-fragments - Cell Death Detection ELISA Plus $(11,774,425,001$ ROCHE) according to the manufacturer's protocol.

The cells were briefly seeded on 96 wells plate, grown for $24 \mathrm{~h}$ and then treated with selected inhibitors, either individual or in combinations, as well as with vehicle (DMSO) as the control. After the incubation period, the cell culture medium was discarded, the cells were lysed, and the lysates were centrifuged in order to eliminate intact cell nuclei. Next, the supernatant with histone-linked DNA fragments was applied on streptavidin-coated microplate well, incubated with immunoreagent, and then treated with a substrate to receive colorimetric signal (A405; BIO-TEK Synergy HT Plate Reader). The results are presented as mean absorbance value (405 $\mathrm{nm}$ ) which reflects the amount of mono- and oligonucleosomes released to the cytoplasm of apoptotic cells. Furthermore, as per the manufacturer's instruction, the enrichment factor (EF) was calculated to estimate the fold increase of DNA fragmentation in the treated samples with reference to the control one.

\section{Cell proliferation}

The proliferation of cells was assessed with the crystal violet test as previously described (Ciołczyk-Wierzbicka et al. 2012). 


\section{Cytotoxicity assay}

Cytotoxicity of selected kinases' inhibitors: AKT - MK-2206 $(2 \mu \mathrm{M})$, MEK - AS-703026 $(10 \mu \mathrm{M})$, PI3K - LY294002 $(20 \mu \mathrm{M})$, ERK1/2 - U0126 $(10 \mu \mathrm{M})$, mTOR - everolimus (20 nM, $2 \mu \mathrm{M}, 5 \mu \mathrm{M}$ and $10 \mu \mathrm{M}$ ) was determined using Cytotoxicity Detection Kit LDH (Roche, Germany).

\section{Western blot analysis}

Samples for SDS-PAGE electrophoresis were prepared in the same way as previously described (Ciołczyk-Wierzbicka et al. 2012). Antibodies against Phospho-Bcl-2 (Ser70) (SH2) \#2827, Phospho-Bcl-2 (Thr56) \#2875, Bcl-2 (D55G8) 4223\#, Bcl-xl (54H6) 2764\#, Mcl-1 (D35A5) 5453\# (Cell Signaling Technology), and $\beta$-actin (A2228, SIGMA) were used to detect the indicated proteins. Bands were visualized with the use of horseradish peroxidase-coupled secondary anti-mouse or anti-rabbit antibody (Cell Signaling Technology). Immunoreactivity of protein was detected with the use of chemiluminescence, and images were captured with a ChemiDoc MP Imaging System (Bio-Rad Labs). To obtain quantitative results, immunoblots were scanned with the use of SynGene Gene Tools version 4.03.0 (Synoptics Ltd. Beacon House, Nuffield Road Cambridge, CB4 1TF, UK). Densitometry was performed to normalize to $\beta$-actin protein level. Presented are representative membranes of at least three independent experiments.

\section{Densitometry analysis}

Densitometry of western blot analysis was performed with the use of SynGene Gene Tools version 4.03.0 (Synoptics Ltd. Beacon House, Nuffield Road Cambridge, CB4 1TF, UK) and the results were normalized to $\beta$-actin protein level. Presented are representative membranes of at least three independent experiments with similar results.

\section{Statistics}

Statistical analyses were performed using one-way ANOVA with post-hoc Dunett test (Statistica 12.0 StatSoft). The statistical significance is presented in Figures.

\section{Results}

\section{Cytotoxicity assay}

In all examined melanoma cell lines, inhibitors:: AKT MK-2206 $(2 \mu \mathrm{M})$, MEK - AS-703026 (10 $\mu \mathrm{M})$, PI3K LY294002 $(20 \mu \mathrm{M})$, ERK1/2 - U0126 $(10 \mu \mathrm{M})$, mTOR everolimus ( $20 \mathrm{nM}, 2 \mu \mathrm{M}, 5 \mu \mathrm{M}$ and $10 \mu \mathrm{M})$ showed no cytotoxicity effect in the $24 \mathrm{~h}$ of treatment. LDH activity in the culture medium in no case exceeded $3,8 \%$; however, after $72 \mathrm{~h}$ treatment, the effect of cytotoxicity was noticed for combinations of inhibitors: AS-703026 with LY294002 (13\%), and MK-2206 with U126 (11\%). Increased lactate dehydrogenase activity for the WM266-4 cell line for combination of inhibitors: AS-703026 and MK-2206 $(7,1 \%)$ was also observed.

\section{Expression Bcl-2 family pro-survival protein}

The current study focuses on the comparison of the influence of mTOR inhibitor everolimus, and proteins kinase inhibitors: AKT - MK-2206, PI3K - LY294002 and ERK1/2 - U126 and their combinations on the expression of pro-survival proteins: p-Bcl-2 (S70), p-Bcl-2 (T56), Bcl-2, Bcl-xL, and Mcl-1 in metastatic (WM 266-4) and primary (WM 115) melanoma cell lines (Fig. 1).

The protein kinase inhibitors, when used individually, produced a decrease in the expression of pro-survival proteins, whereas, their combinations had significantly more pronounced effects (Fig. 1).

The most visible effect of melanoma cells treatment with single inhibitor on the protein expression level of $p$ Bcl-2 (S70) and p-Bcl-2 (T56) was observed after incubation with MEK inhibitor - AS-703026 or PI3K inhibitor LY294002, slightly weaker being that for ERK1/2 inhibitor - U126 or AKT - MK-2206 (Fig.1). The expression level of total Bcl-2 also decreased in WM 266-4 and WM 115 cell lines. Additionally, AS-703026 inhibitor significantly reduced the expression level of Bcl-xL (by about 70\%) in WM 266-4 (Fig. 1b).

Moreover, the combinations of inhibitors significantly affected the expression level of analysed pro-survival proteins. The most significant, nearly $100 \%$ reduction, was observed in WM 266-4, and 80\% decrease in WM 115 after their treatment with combination of MEK inhibitor AS-703026 and PI3K - LY294002 (Fig.1). Slightly worse results were obtained for the combination of inhibitors: AS-703026 with MK-2206, and MK-2206 with U126 in both melanoma cell lines (Fig. 1).

The effect of different doses of everolimus $(20 \mathrm{nM}$, $2 \mu \mathrm{M}, 5 \mu \mathrm{M}$, and $10 \mu \mathrm{M}$ ) as well as the combination of everolimus ( $20 \mathrm{nM}$ and $10 \mu \mathrm{M})$ with AS-703026 and MK2206 on the expression of pro-survival proteins was also evaluated. The most visible reduction of the expression level of studied proteins was observed after treatment of WM115 and WM266-4 with $10 \mu \mathrm{M}$ everolimus. (Fig. 2). However, its $5 \mu \mathrm{M}$ concentration reduced Mcl-1 expression by almost $100 \%$ in WM 266-4. Addition of AS703026 to $10 \mu \mathrm{M}$ everolimus contributed to the most significant reduction of apoptotic proteins expression levels in both melanoma cell lines where all evaluated proteins were 
Fig. 1 Expression of pro-survival proteins in: WM115 (a) andWM266-4 (b). Western blot analysis was performed in accordance with Materials and

Methods. Densitometry analyses of western blot were performed on raw volume (sum of intensities of bound-volume calculated from the area of the peak) using SynGene Gene Tools version 4.03.0 (Synoptics Ltd. Beacon House, Nuffield Road Cambridge, CB4 1TF, UK). Densitometry results were normalized to control (melanoma cells untreated with protein kinase inhibitors). Presented are representative of at least three independent experiments

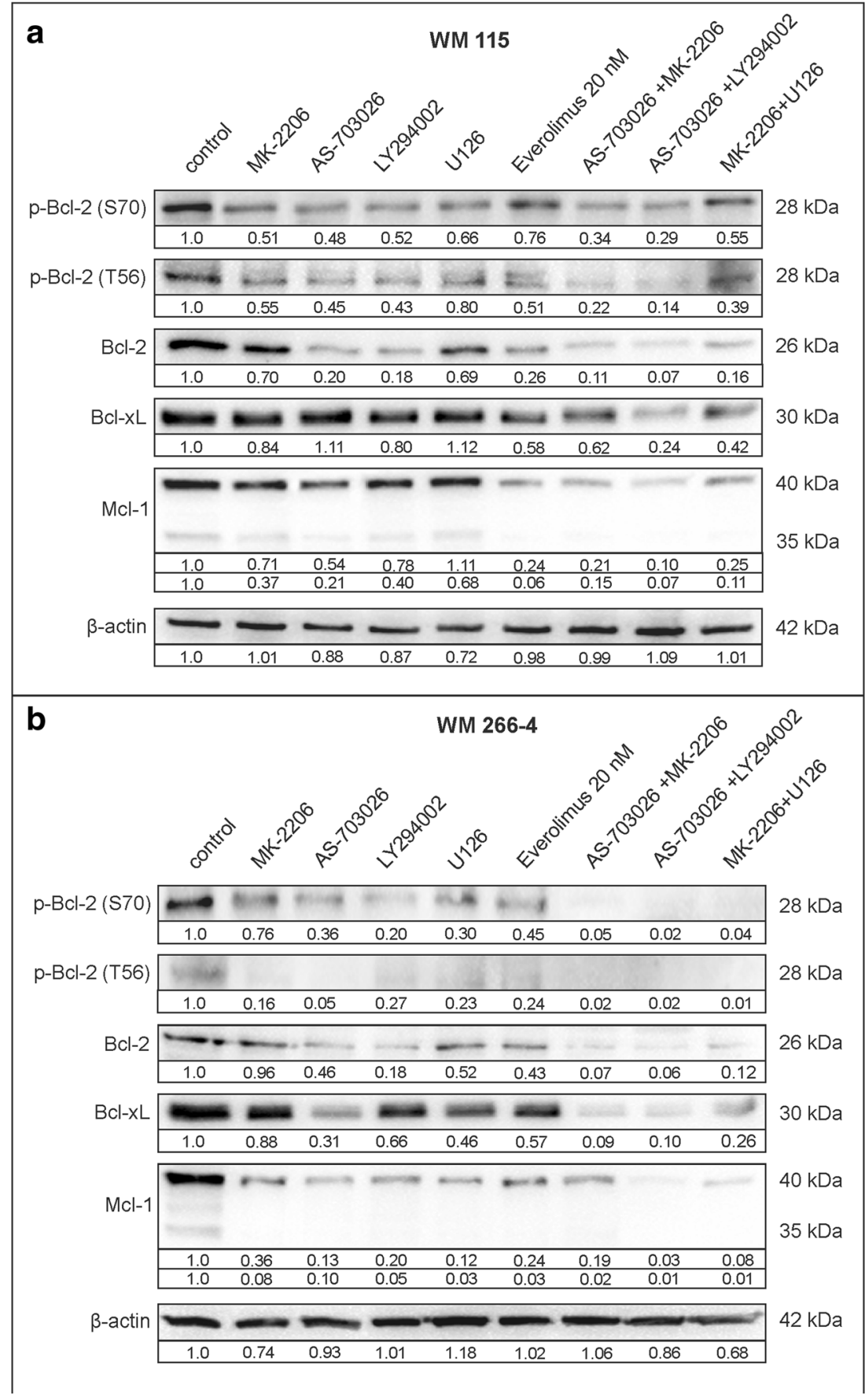

reduced by more than $80 \%$. This effect was also evident at $20 \mathrm{nM}$ everolimus concentration (Fig. 2). Somewhat surprisingly, a slight increase in the expression of Bcl-2, Bcl-2 (S70) and Bcl-xL in WM266-4 using a combination of $20 \mathrm{nM}$ everolimus and MK-2206 was noted. The use of AKT inhibitor - MK2206 in combination with an mTOR inhibitor everolimus was less effective; however, the clearcut effect was observed at everolimus $10 \mu \mathrm{M}$ concentration, the highest level used (Fig. 2).

\section{Caspase-3 activity and cell proliferation in melanoma cell lines}

Investigated was also the effect of protein kinases' inhibitors: AKT - MK-2206, MEK - AS-703026, PI3K LY294002 and ERK1/2 - U126 and mTOR - everolimus in a single mode, and their combinations on caspase- 3 activation and proliferation in WM266-4 and WM115 melanoma cell lines. 
Fig. 2 The effect of treatment of melanoma cells with everolimus on expression of pro-survival Bcl2 family protein. Western blot analysis of: WM115 (a) andWM266- 4 (b) melanoma cell lines. Densitometry analyses of western blot were performed on raw volume (sum of intensities of bound-volume calculated from the area of the peak) using SynGene Gene Tools version 4.03.0 (Synoptics Ltd. Beacon House, Nuffield Road Cambridge, CB4 1TF, UK). Densitometry results were normalized to control (melanoma cells untreated with protein kinase inhibitors). Presented are representative of at least three independent experiments

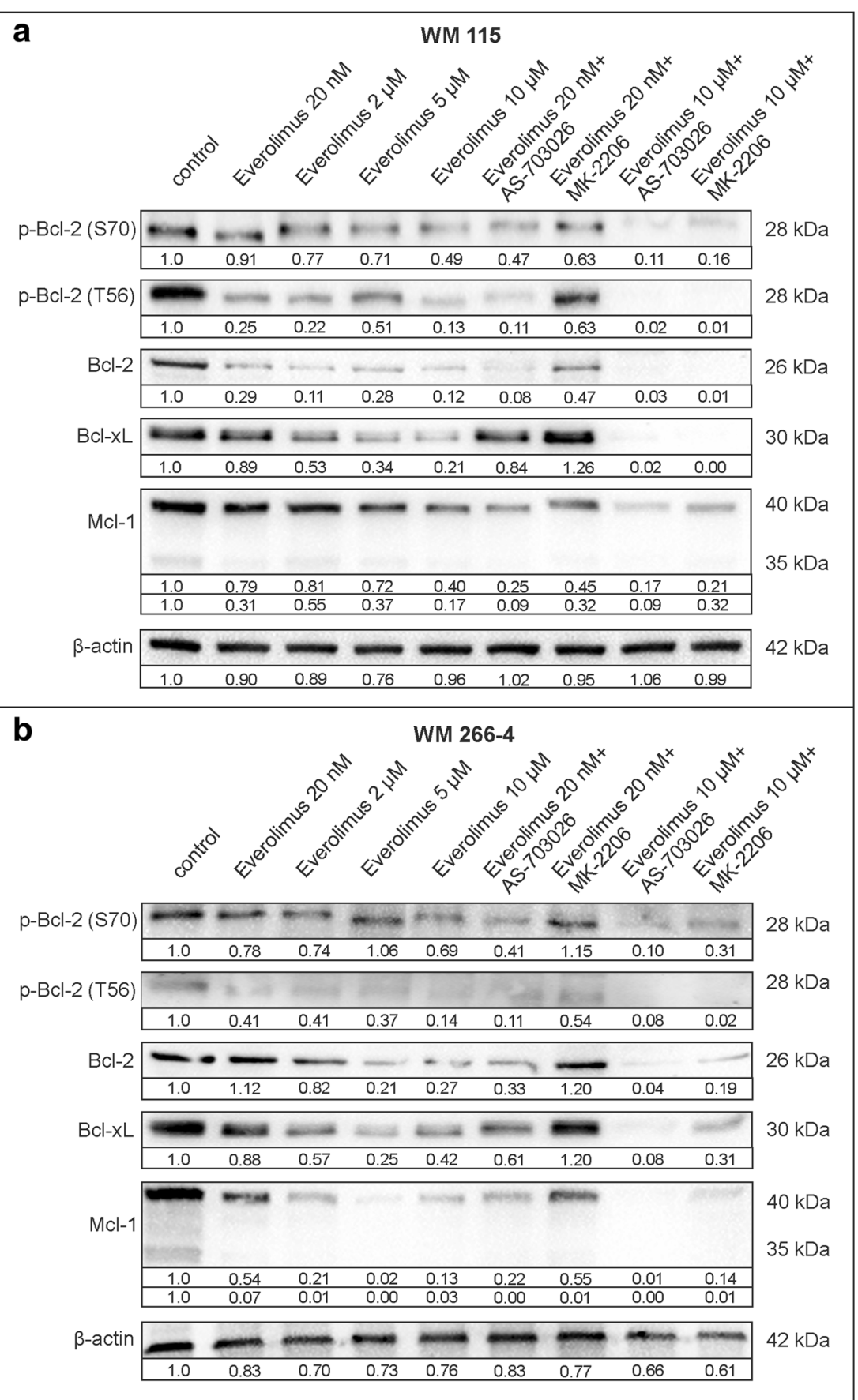

The highest increases of caspase- 3 activity in the case of individually-used protein kinase inhibitors were observed for both cell lines after application of MEK kinase inhibitor - AS703026. A weaker yet meaningful effect occurred for ERK1/2 inhibitor - U126. A few-fold, although not particularly significant, increase of caspase-3 activity was also observed for AKT inhibitor - MK-2206 and PI3K - LY294002 (Fig. 3a). For both melanoma cell lines, treatment with protein kinase inhibitors was accompanied by a decrease in proliferation: highest after the use of the AKT inhibitor - MK2206 (about
40\%), and slightly smaller for inhibitors of the MAP kinase pathway, AS-703026 or U126 (Fig. 3b).

The combination of inhibitors was accompanied by substantially higher increases of caspase-3 activity. The combination of MEK inhibitor - AS-703026 and AKT inhibitor - MK2206 led to up to 35 -fold increase of caspase-3 activity $(p<0.001)$, whereas somewhat lower, 15-fold $(p<0.001)$, was observed for the combination of the MEK inhibitor AS-703026 and PI3K inhibitor - LY294002 ( $p<0.001)$. Still a high, but much lower increase was noticed for the 


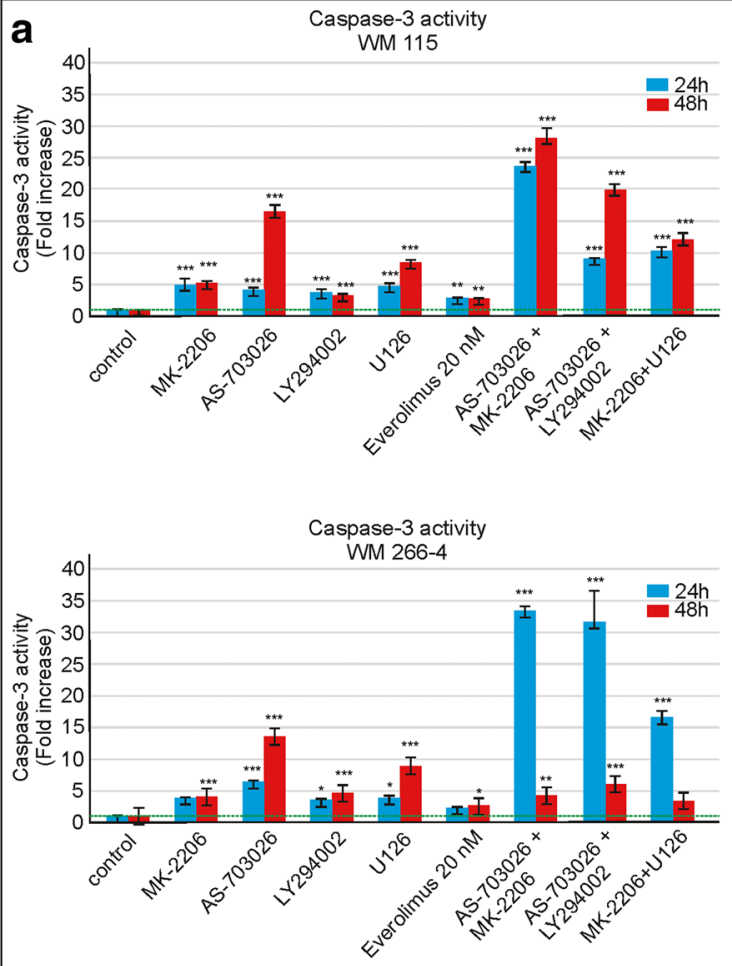

Fig. 3 The effect of protein kinase inhibitors on caspase-3 activity and cell proliferation in WM115 and WM266-4 melanoma cell lines. The caspase-3 activity (a) and cell proliferation - crystal violet assay (b) were calculated from mean values of three independent experiments. Statistical

combination of inhibitors: ERK1/2 - U126 with AKT- MK$2206(p<0.001)$ (Fig. 3a). $48 \mathrm{~h}$ treatment yielded a higher increase of caspase- 3 activity in comparison to $24 \mathrm{~h}$ treatment in each case of inhibition, except for the use of the combination of inhibitors in line WM266-4, suggesting faster caspase3 activation in this cell line (Fig. 3a).

In the case of proliferation, the greatest decrease was observed for the combination of inhibitors: MK-2206 with U126 for WM266-4 cell line (about 63\%), and AS-703026 with MK-2206 for WM115 cell line (about 55\%) (Fig. 3b).

In addition, the effect of mTOR inhibitor everolimus on caspase-3 activity and proliferation was studied in the range between $20 \mathrm{nM}$ and $10 \mu \mathrm{M}$ concentration. As the inhibitor concentration increased, so did caspase-3 activity in both cell lines, reaching the highest value of about 10-fold increase relative to the control $(p<0.001)$ for the highest tested concentration of everolimus - $10 \mu \mathrm{M}$ (Fig. 4a). The use of a mTOR inhibitor everolimus $(10 \mu \mathrm{M})$ in combination with MEK one - AS-703026 resulted in approximately 25 -fold increase of caspase-3 activity $(p<0.001)$. Slightly lower, 15 fold effect $(p<0.001)$, was observed for $20 \mathrm{nM}$ concentration of everolimus (Fig. 4b).

In contrast, cell proliferation decreased with increasing everolimus concentration regardless of the mode of its use:

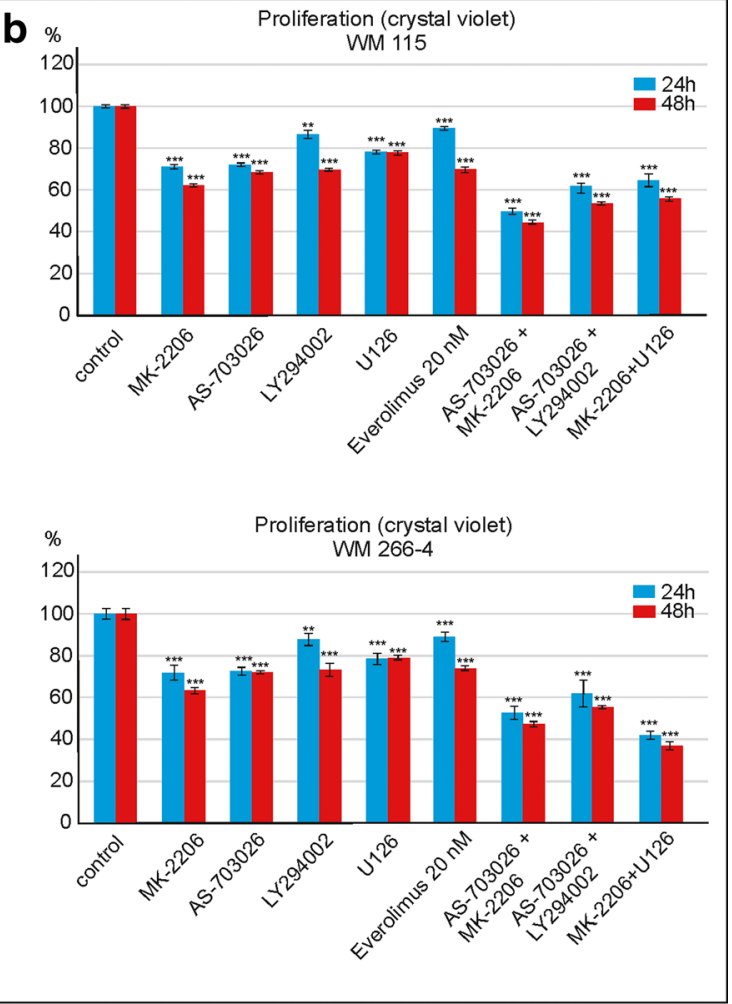

analyses were performed using one-way ANOVA with post-hoc Dunett test (Statistica 12.0 StatSoft); significant difference: $(*) p<0.05,(* *)$ $\left.p<0.01,{ }^{* * *}\right) p<0.001$

individual or in combinations. $10 \mu \mathrm{M}$ everolimus combined with the MK-2206 inhibitor led to a decrease of proliferation (about 55\%), and to a comparable effect for the combination with MEK inhibitor - AS-703026 (Fig. 4b).

\section{DNA fragmentation ELISA assay - detection of apoptosis}

In order to verify apoptosis induction in the selected samples that were assayed for caspase-3 activity, the cell death detection ELISA assay which reflects DNA fragmentation in apoptotic cells was performed. As demonstrated in Fig. 5a, in the case of WM115 melanoma cells, none of the inhibitors used individually was considerably effective in apoptosis triggering except MEK inhibitor AS-703026, which led to about 4-fold $(p<0.01)$ enrichment in fragmented DNA content.

The highest level of DNA apoptotic degradation was observed in response to concurrent application of MEK inhibitor - AS-703026 with AKT kinase inhibitor - MK-2206 as well as mTOR inhibitor everolimus with MEK inhibitor- AS703026 (Fig. 5a). It manifested by significant increase in absorbance value as compared to an untreated sample, with the enrichment factor (EF; calculated to estimate the fold increase of DNA fragmentation in treated samples with reference to 


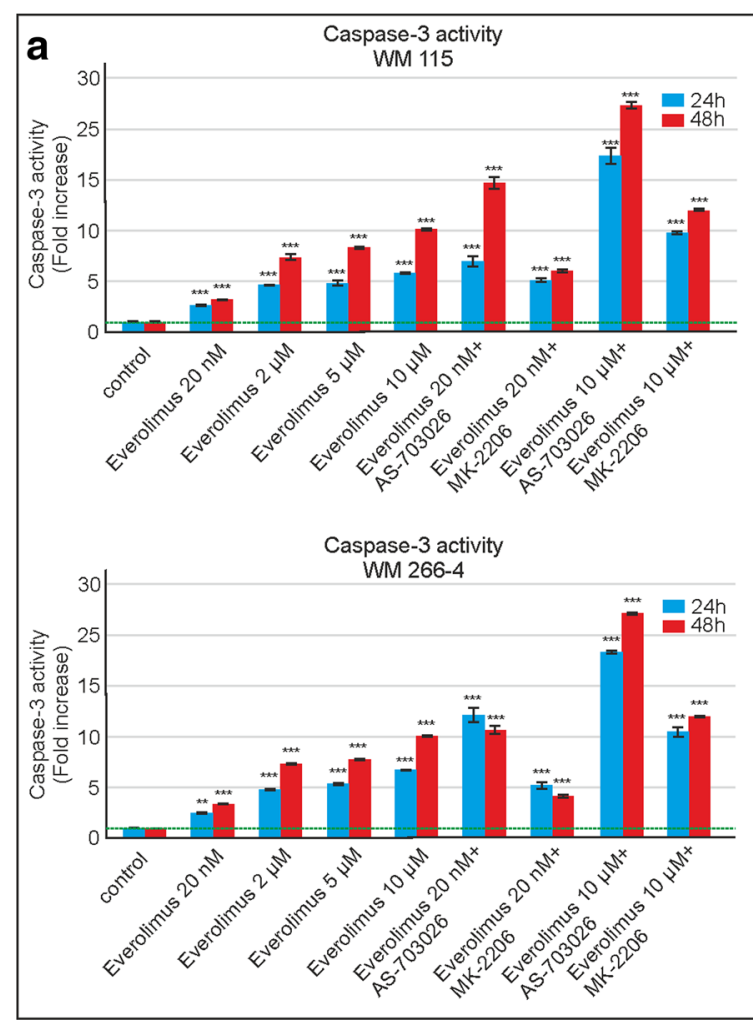

Fig. 4 The effect of everolimus on caspase-3 activity and cell proliferation in: WM115 and WM266-4 melanoma cell lines. The effect of caspase-3 activity (a) and cell proliferation - crystal violet assay (b) were calculated from mean values of three independent experiments. Statistical

control one) reaching 13,5 $(p<0.001) ; 11,7(p<0.001)$ and $11,3(p<0.001)$ for MEK inhibitor - AS-703026 combined with AKT kinase inhibitor - MK-2206, $20 \mathrm{nM}$ everolimus combined with MEK inhibitor - AS-703026 and $2 \mu \mathrm{M}$ everolimus combined with MEK inhibitor - AS-703026, respectively. The data seem to suggest a synergistic effect of the applied agents. Unexpectedly, further increase of everolimus concentration in combination with AS-703026, both to $5 \mu \mathrm{M}$ as well as to $10 \mu \mathrm{M}$ was not followed by enhancement of apoptosis, showing even lower EF $(8,0(p<0.001)$ and 9,6 $(p<0.001)$ respectively).

Combination of mTOR inhibitor everolimus with AKT kinase inhibitor - MK-2206 was about 2-fold, less effective in comparison to everolimus and MEK inhibitor - AS-703026. Independently of everolimus concentration $(2,5,10 \mu \mathrm{M})$, the EF value oscillated around 4. An exception was the combination with the lowest everolimus concentration $(20 \mathrm{nM})$, in which case the EF value reached 5,9 $(p<0.001)$.

Similarly, in the case of WM266-4 melanoma cells (Fig. $5 b$ ), each of the inhibitors used individually was hardly effective in apoptosis induction, with the exception of MEK inhibitor - AS-703026, as manifested by high EF value ( $\sim 35$, $p<0.001)$. Nevertheless, combining MEK inhibitor - AS703026 with AKT kinase inhibitor - MK-2206 did not result

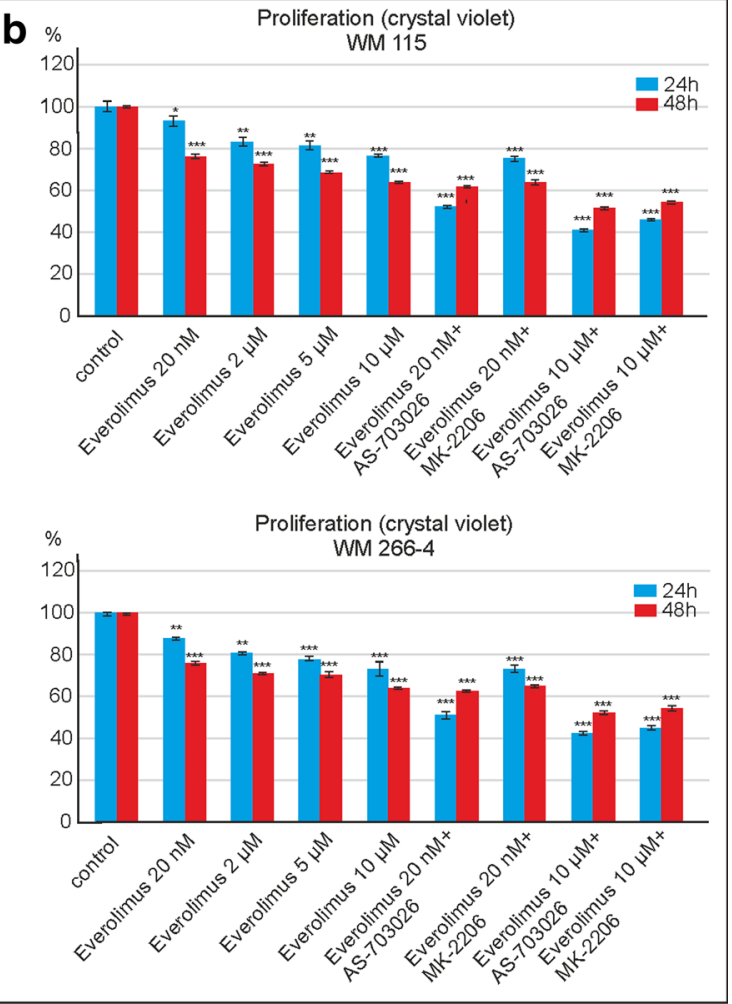

analyses were performed using one-way ANOVA with post-hoc Dunett test (Statistica 12.0 StatSoft); significant difference: $(*) p<0.05,(* *)$ $\left.p<0.01,{ }^{* * *}\right) p<0.001$

in such a significant enhancement as observed in WM115 cells line (Fig. 5b).

The most potent apoptosis induction was observed following concurrent application of $20 \mathrm{nM}$ everolimus with MEK inhibitor - AS-703026, the EF of which equalled 163,3 $(p<0.001)$, which strongly suggests their synergistic cooperation (Fig. 5b). Surprisingly, a further increase of everolimus concentration $(2-10 \mu \mathrm{M})$ led rather to a considerable decrease of DNA fragmentation in those cells. Still, the EF values were remarkably high $(136.8-68,5 ; p<0.001)$. The effectiveness of all combinations with AKT kinase inhibitor - MK-2206 was similar, independently of the type and concentration of the accompanying inhibitor and was manifested by high $\mathrm{EF}$ value in the range of 70-97 $(p<0.001)$ (Fig. 5b). Besides MEK inhibitor - AS-703026 and AKT kinase inhibitor-MK-2206, all the other combinations seem to indicate synergistic effects on apoptosis induction in WM266-4 melanoma cells (Fig. 5b).

\section{Discussion}

Activation of PI3K/AKT and mTOR pathways is the main development mechanism in many types of cancer, therefore their inhibitors are a promising target in the search for new 


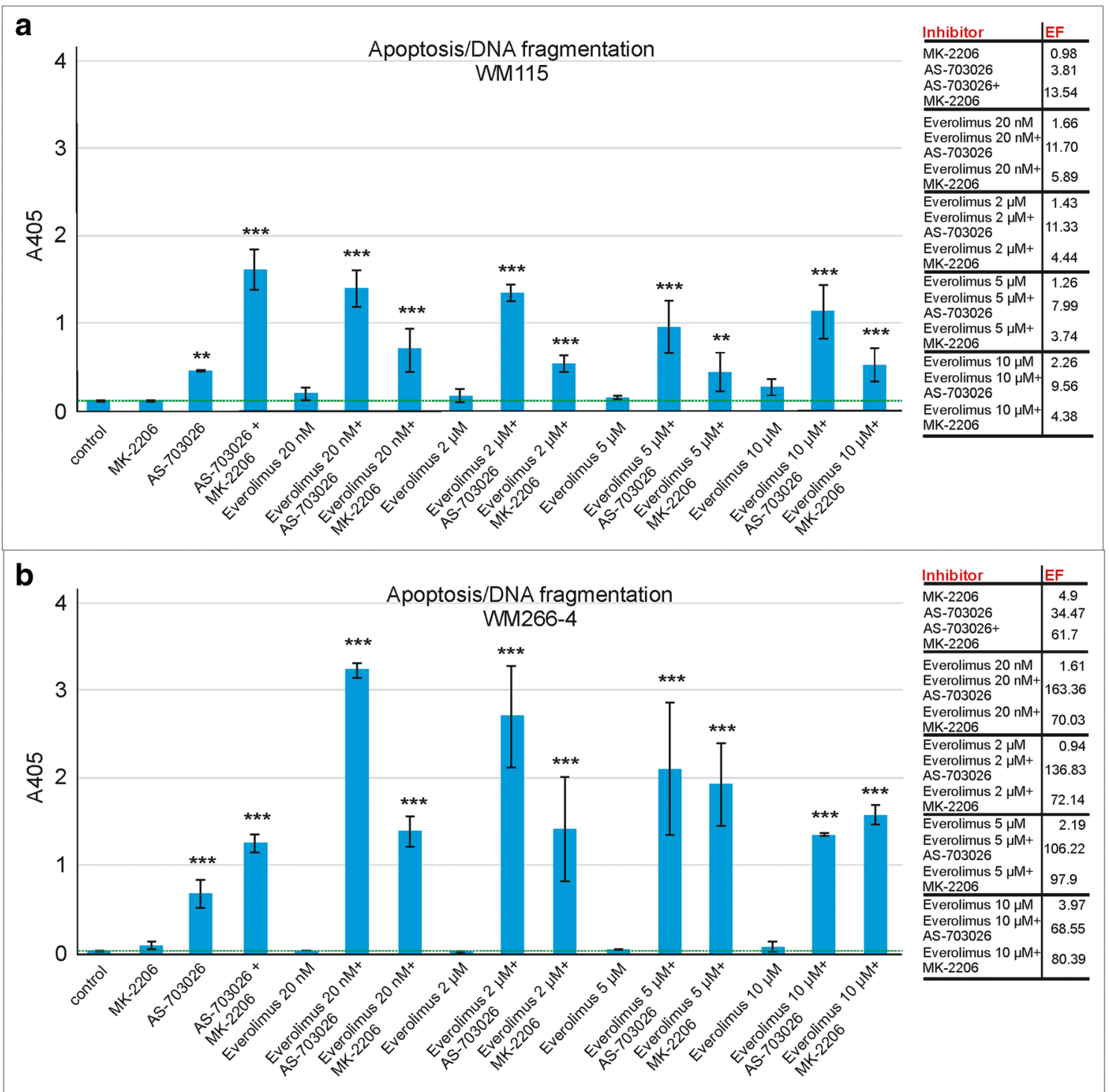

Fig. 5 The effect of protein kinase inhibitors on melanoma cell apoptosis - WM115 (a) and WM266-4 (b). Apoptosis was detected as photometric enzyme-immunoassay for the qualitative and quantitative in vitro determination of cytoplasmic histone-associated-DNA-fragments (mono- and oligonucleosomes). Effect of protein kinase inhibitors and their combinations on apoptosis induction evaluated by the mean of DNA fragmentation ELISA assay after $24 \mathrm{~h}$ treatment of melanoma cells. Error bars

treatment strategies (Woo et al. 2017). However, the modest antitumour effect of single-agent therapies suggests a need for drug combinations which could reduce their concentrations without the loss of activity in the pursuit of superior clinical responses.

Many literature reports (Ji et al. 2017; Woo et al. 2017) confirm the antitumour efficacy of mTOR inhibitor rapamycin or another rapalog in combination with highly selective AKT inhibitor - MK2206 in inhibition of proliferation, tumour growth and induction of apoptosis in many types of cancers such as: lymphoblastic leukemia, cholangiocarcinoma, represent SD. The enrichment factor $(\mathrm{EF})$ was calculated to estimate the fold increase of DNA fragmentation in treated samples with reference to control one. The graphs present mean values of representative experiments performed in duplicates. Statistical analyses were performed using one-way ANOVA with post-hoc Dunett test (Statistica 12.0 StatSoft); significant difference: $(*) p<0.05,(* *) p<0.01,(* * *) p<0.001$

hepatocellular carcinoma, neuroblastoma, gastric cancer, and thyroid cancer.

Our previous studies (Ciołczyk-Wierzbicka and Laidler 2018; Ciołczyk-Wierzbicka et al. 2018) regarding the treatment of melanoma cells with mTOR inhibitors, found that both rapamycin and everolimus had a significant impact on cell cycle regulation, cell proliferation, and invasive potential.

We recently demonstrated that treatment of various melanoma cells with low concentration $(5 \mathrm{nM})$ of mTOR inhibitor everolimus resulted in significantly reduced cell proliferation and diminished number of cancer cells (Ciołczyk-Wierzbicka 
et al. 2018). It also led to the reduction of metalloproteinase's (MMPs) activity, as well as reduced invasion, especially when everolimus was used in combination with PI3K/AKT or MEK inhibitors (Ciołczyk-Wierzbicka and Laidler 2018).

The promising preliminary results regarding the use of the mTOR inhibitor everolimus led to the continuation of research on the effects of this agent on pro-survival Bcl-2 family proteins expression. Caspase-3 activity, proliferation, and induction of apoptosis in melanoma cells.

\section{Expression of pro-survival Bcl-2 family proteins, caspase-3 activity and reduction of cell proliferation}

Resistance to apoptosis is an important hallmark of melanoma (Grazia et al. 2014). Enhanced apoptotic cell death is manifested, among others, by: activation of caspase-3, activation pro-apoptotic proteins, and down-regulation of pro-survival protein such as of Bcl-2 and Mcl-1 (Grazia et al. 2014).

Observed was a significant decrease in the expression of studied pro-survival Bcl-2 family proteins: p-Bcl-2 (Ser70), p-Bcl-2 (Thr56), Bcl-2, Bcl-xl, and Mcl-1 after the use of protein kinase inhibitors, which is particularly meaningful when using their combinations. A slight increase in the expression of Bcl-2 and Bcl-2 phosphorylated at serine 70 in the WM266-4 cells after simultaneous blocking of the kinase mTOR pathway (20 nM everolimus) and AKT kinase (MK-2206) may indicate the emergence of drug resistance mechanisms. Observations based on acute myeloid leukaemia [Konopleva et al. 2006] suggest that $\mathrm{Mcl}-1$ expression and basal Bcl-2 phosphorylation may contribute to the drug resistance. During our studies, a decrease in Mcl-1 protein was observed, especially after inhibition of the MEK kinase inhibitor AS-703026, both alone and together with the mTOR - everolimus inhibitor.

In the case of single protein kinase inhibitors, a significant increase in caspase- 3 activity was observed after the use of the MEK kinase inhibitor AS-703026; slightly less profound yet similar effect occurred for the ERK1/2 inhibitor - U126. The increase of caspase-3 activity was also observed for the AKT - MK-2206 and PI3K - LY294002 inhibitors.

According to Kim et al. (2010), inhibition of proliferation induced by AS-703026 was mediated by G0-G1 cell cycle arrest and was accompanied by induced apoptosis via caspase- 3 and Poly ADP ribose polymerase (PARP) cleavage in multiple myeloma cells, both in the presence and absence of bone marrow stromal cells. Results obtained by Park et al. (2013) suggest that the treatment of malignant melanoma cells (harbouring mutation V600E and resistance to B-RAF inhibitors) with a combination of B-RAF - PLX4032 and MEK AS-703026 inhibitors significantly induced apoptosis and caspase- 3 expression. The use of each of these agents alone was not marked with high efficiency (Park et al. 2013).

Here, the use of combinations of inhibitors gave significantly better results than the use of single inhibitors in terms of suppressing the expression of pro-survival proteins, increasing activity of caspase- 3 , and decreasing cell proliferation. The observed increase in caspase- 3 activity was significantly higher after $48 \mathrm{~h}$ treatment, except for the use of the combination of PI3K/AKT and MEK inhibitors in WM266-4 cell line, for which this combination of inhibitors led to elevated LDH activity. In this cell line, observed was a higher increase in caspase- 3 activity in a shorter period ( $24 \mathrm{~h})$, which indicates a faster activation of caspase- 3 in this cell line. All this could suggest that the combination of PI3K/AKT and MEK inhibitors caused lysis of WM266-4 cells in addition to their apoptosis.

The treatment of melanoma cells with mTOR inhibitor everolimus ( $20 \mathrm{nM}$ to $10 \mu \mathrm{M}$ concentrations) gave promising results, similar to those regarding the effect of this inhibitor on the cell cycle, proliferation, and invasiveness (CiołczykWierzbicka and Laidler 2018; Ciołczyk-Wierzbicka et al. 2018). The low concentration of the mTOR inhibitor everolimus $(20 \mathrm{nM})$ led to a significant decrease in the expression of all pro-survival Bcl-2 family proteins.

The results obtained by Du et al. (2018) show that everolimus treatment decreased expression of Bcl-2 gene in breast cancer cells.

The use of a combination of mTOR inhibitor - rapamycin and AKT inhibitor - MK-2206 has been described by many research groups that reported a reduction of cell growth, blockade of cell cycle progression, and enhanced apoptosis in different melanoma models (humans, murine and canine) (Grazia et al. 2014).

Numerous data show decreased cell proliferation and increased caspase- 3 activity after the use of mTOR inhibitors in many cases of tumours such as pancreatic (Peng and Dou 2017), breast (Woo et al. 2017), and colon cancer (He et al. 2016).

Here, everolimus concentration was found to remain in inverse proportion to proliferation of melanoma cells - the higher the former, the lower the latter. The combination of $10 \mu \mathrm{M}$ concentration of everolimus with the MK-2206 inhibitor resulted in the decrease in proliferation by $55 \%$. A slightly lower decrease was observed for the combination with AS703026 inhibitor.

\section{Apoptosis}

Based on the results obtained for the inhibition of pro-survival proteins and caspase- 3 activity, the most effective protein kinases inhibitors: AS-703026, MK-2206 and various concentrations $(20 \mathrm{nM}$ to $10 \mu \mathrm{M})$ of mTOR inhibitor everolimus were selected with the aim of studying the apoptosis activation in melanoma cells.

Among the single inhibitors used, the MEK inhibitor - AS703026 was the most effective in induction of apoptosis as measured by caspase-3 activation. Similar results were 
obtained for patients with multiple myeloma (Kim et al. 2010; Kim et al. 2017). Results of the study based on human melanoma cell line with B-RAF V600E mutation that are resistant to B-RAF inhibitors confirmed the efficacy of the AS-703026 inhibitor in the induction of apoptosis and its particular efficacy in combination with the B-RAF inhibitor - PLX4032 (Park et al. 2013).

Herein demonstrated is the fact that everolimus in $10 \mu \mathrm{M}$ concentration was even more effective than the AKT inhibitor -MK-2206 for the primary melanoma cell line - WM115, while low concentrations of the everolimus induced apoptosis in melanoma cells at a very low level. Everolimus (and another rapalogs) induces apoptosis in a variety of tumours cells: pancreatic cancer (Peng and Dou 2017), ovarian cancer (Guo et al. 2016), colon cancer (He et al. 2016), breast cancer (Du et al. 2018), N-RAS mutant neuroblastoma cell lines (Kiessling et al. 2016), and $\mathrm{T}$ cell leukemia/lymphoma in long-term treatment (Darwiche et al. 2011), however in some tumours its high concentration stimulates a caspase-independent pathway - autophagy cell death (Nikoletopoulou et al. 2013; Lui et al. 2016). Autophagy is the process related to cancer progression (Mowers et al. 2017). High level of autophagy can be observed in some rapidly growing cells (Neufeld 2012) and in cells losing cellular adhesion (Dower et al. 2018). Autophagy may also sensitize tumour cells to anticancer drugs (Paquette et al. 2018). The effect of treatment of WM266-4 cells with $10 \mu \mathrm{M}$ everolimus suggests that high concentration of this rapalog, similarly to PI3K kinase inhibitors and other activators (Milinkovic et al. 2018), might have induced autophagy in the studied metastatic cells (WM266-4).

It is noteworthy that the very low concentrations of the everolimus inhibitor $(20 \mathrm{nM})$ in combination with the MEK inhibitor - AS-703026 led to very significant apoptotic effects. The results presented by Zeng et al. (2018) show that the combination of everolimus and AZD6244 - a highly selective ERK inhibitor, significantly enhanced apoptosis and impaired the viability of renal carcinoma cells, while high concentrations of everolimus alone induce autophagy in these cells. Kiessling et al. (2016) showed that mTOR inhibitor everolimus in single mode use reduces cell growth and leads to apoptosis in N-RAS mutant neuroblastoma cell lines, and in combination with MEK inhibitor produced a synergistic effect and could be important in future clinical studies.

The results obtained by He et al. (2016) regarding the use of high concentrations of everolimus $(10-25 \mu \mathrm{M})$ in colon cancer cells with the BRAF V600E and K-RAS mutation showed that they are unlikely to respond to monotherapy targeting mTOR inhibitor, but might benefit from combination therapy with PI3K, RAF or MEK inhibitors.

Results of studies from many centres on a panel of human cancer cell lines of different histological origin confirmed the role of PTEN status in determining pharmacological interactions between RAF/MEK and PI3K/AKT/mTOR pathways inhibitors (Weeber et al. 2017; Sathe et al. 2018; Milella et al. 2017). PTEN-loss allowed effective prediction of synergistic inhibitory growth interactions between RAF/MEK and PI3K/AKT/mTOR inhibitors (Milella et al. 2017).

A similar, but lower effect was also observed here for the combination of AKT inhibitor - MK-2206 and everolimus. This combination was more effective in inhibiting melanoma cell proliferation. Our recent study showed that this combination of protein kinase inhibitors had a very promising effect on inhibiting the invasiveness and activity of metalloproteinase 2 and 9 (Ciołczyk-Wierzbicka and Laidler 2018).

MK-2206, a potent oral allosteric AKT inhibitor that enhances the antitumour potency of chemotherapeutic agents ( $\mathrm{Ji}$ et al. 2017), had no effect on normal peripheral blood mononuclear cells, but induced G1-phase arrest and apoptosis in leukemia cells ( $\mathrm{Lu}$ et al. 2015), and induction of apoptosis by combined treatment of bufalin in multiple myeloma cells (Xiang et al. 2017).

The herein reported nanomolar concentration of mTOR inhibitor everolimus in the combination with inhibitor of MAP kinase (AS-703026) or AKT kinase (MK-2206) pathway are sufficient to induce apoptosis, and reduce proliferation and invasiveness in melanoma cells. The result seems very important and promising on account of the low concentrations of inhibitors. One can hope that such an approach will find recognition and application in the near future.

Acknowledgements This work was supported by a grant from the Ministry of Science and Higher Education through Jagiellonian University Medical College K/ZDS/006458.

\section{Compliance with ethical standards}

Conflict of interest The authors declare that they have no conflict of interest.

Human and animal rights This article does not contain any studies with human participants or animals performed by any of the authors.

Open Access This article is distributed under the terms of the Creative Commons Attribution 4.0 International License (http:// creativecommons.org/licenses/by/4.0/), which permits unrestricted use, distribution, and reproduction in any medium, provided you give appropriate credit to the original author(s) and the source, provide a link to the Creative Commons license, and indicate if changes were made.

Publisher's note Springer Nature remains neutral with regard to jurisdictional claims in published maps and institutional affiliations.

\section{References}

Barrett D, Brown VI, Grupp SA, Teachey DT (2012) Targeting the $\mathrm{PI} 3 \mathrm{~K} / \mathrm{AKT} / \mathrm{mTOR}$ signaling axis in children with hematologic malignancies. Paediatr Drugs 14(5):299-316. https://doi.org/10.2165/ 11594740-000000000-00000 
Ciołczyk-Wierzbicka D, Laidler P (2018) The inhibition of invasion of human melanoma cells through N-cadherin knock-down. Med Oncol 35(4):42

Ciołczyk-Wierzbicka D, Gil D, Laidler P (2012) The inhibition of cell proliferation using silencing of $\mathrm{N}$-cadherin gene by siRNA process in human melanoma cell lines. Curr Med Chem 19(1):145-151

Ciołczyk-Wierzbicka D, Gil D, Laidler P (2018) Treatment of melanoma with selected inhibitors of signaling kinases effectively reduces proliferation and induces expression of cell cycle inhibitors. Med Oncol 35(1):7. https://doi.org/10.1007/s12032-017-1069-0

Conciatori F, Ciuffreda L, Bazzichetto C, Falcone I, Pilotto S, Bria E, Cognetti F, Milella M (2018) mTOR cross-talk in cancer and potential for combination therapy. Cancers 10(1):23. https://doi.org/10. 3390/cancers 10010023

Darwiche N, Sinjab A, Abou-Lteif G, Chedid MB, Hermine O, Dbaibo G, Bazarbachi A (2011) Inhibition of mammalian target of rapamycin signaling by everolimus induces senescence in adult $\mathrm{T}$ cell leukemia/lymphoma and apoptosis in peripheral T-cell lymphomas. Int J Cancer 129(4):993-1004. https://doi.org/10.1002/ijc. 25742

Dower CM, Wills CA, Frisch SM, Wang HG (2018) Mechanisms and context underlying the role of autophagy in cancer metastasis. Autophagy. 14(7):1110-1128. https://doi.org/10.1080/15548627. 2018.1450020

Du L, Li X, Zhen L, Chen W, Mu L, Zhang Y, Song A (2018) Everolimus inhibits breast cancer cell growth through PI3K/AKT/mTOR signaling pathway. Mol Med Rep 17(5):7163-7169

Galluzzi L, Vitale I, Aaronson SA, Abrams JM, Adam D, Agostinis P, Alnemri ES, Altucci L, Amelio I, Andrews DW, AnnicchiaricoPetruzzelli M, Antonov AV, Arama E, Baehrecke EH, Barlev NA, Bazan NG, Bernassola F, Bertrand MJM, Bianchi K, Blagosklonny MV, Blomgren K, Borner C, Boya P, Brenner C, Campanella M, Candi E, Carmona-Gutierrez D, Cecconi F, Chan FKM, Chandel NS, Cheng EH, Chipuk JE, Cidlowski JA, Ciechanover A, Cohen GM, Conrad M, Cubillos-Ruiz JR, Czabotar PE, D'Angiolella V, Dawson TM, Dawson VL, de Laurenzi V, de Maria R, Debatin KM, DeBerardinis RJ, Deshmukh M, di Daniele N, di Virgilio F, Dixit VM, Dixon SJ, Duckett CS, Dynlacht BD, el-Deiry WS, Elrod JW, Fimia GM, Fulda S, García-Sáez AJ, Garg AD, Garrido C, Gavathiotis E, Golstein P, Gottlieb E, Green DR, Greene LA, Gronemeyer H, Gross A, Hajnoczky G, Hardwick JM, Harris IS, Hengartner MO, Hetz C, Ichijo H, Jäättelä M, Joseph B, Jost PJ, Juin PP, Kaiser WJ, Karin M, Kaufmann T, Kepp O, Kimchi A, Kitsis RN, Klionsky DJ, Knight RA, Kumar S, Lee SW, Lemasters JJ, Levine B, Linkermann A, Lipton SA, Lockshin RA, López-Otín C, Lowe SW, Luedde T, Lugli E, MacFarlane M, Madeo F, Malewicz M, Malorni W, Manic G, Marine JC, Martin SJ, Martinou JC, Medema JP, Mehlen P, Meier P, Melino S, Miao EA, Molkentin JD, Moll UM, Muñoz-Pinedo C, Nagata S, Nuñez G, Oberst A, Oren M, Overholtzer M, Pagano M, Panaretakis T, Pasparakis M, Penninger JM, Pereira DM, Pervaiz S, Peter ME, Piacentini M, Pinton P, Prehn JHM, Puthalakath H, Rabinovich GA, Rehm M, Rizzuto R, Rodrigues CMP, Rubinsztein DC, Rudel T, Ryan KM, Sayan E, Scorrano L, Shao F, Shi Y, Silke J, Simon HU, Sistigu A, Stockwell BR, Strasser A, Szabadkai G, Tait SWG, Tang D, Tavernarakis N, Thorburn A, Tsujimoto Y, Turk B, vanden Berghe T, Vandenabeele P, Vander Heiden MG, Villunger A, Virgin HW, Vousden KH, Vucic D, Wagner EF, Walczak H, Wallach D, Wang Y, Wells JA, Wood W, Yuan J, Zakeri Z, Zhivotovsky B, Zitvogel L, Melino G, Kroemer G (2018) Molecular mechanisms of cell death: recommendations of the nomenclature committee on cell death. Cell Death Differ 25(3):486-541. https://doi.org/10.1038/ s41418-017-0012-4

Grazia G, Penna I, Perotti V, Anichini A, Tassi E (2014) Towards combinatorial targeted therapy in melanoma: from pre-clinical evidence to clinical application (review). Int J Oncol 45(3):929-949. https:// doi.org/10.3892/ijo.2014.2491

Guo H, Zhong Y, al JAL (2016) Everolimus exhibits anti-tumorigenic activity in obesity-induced ovarian cancer. Oncotarget 7(15):20338 20356. https://doi.org/10.18632/oncotarget.7934

He K, Chen D, Ruan H, Li X, Tong J, Xu X, Zhang L, Yu J (2016) BRAFV600E-dependent Mcl-1 stabilization leads to everolimus resistance in colon cancer cells. Oncotarget 7(30):47699-47710. https://doi.org/10.18632/oncotarget.10277

$\mathrm{Hu}$ W, Kavanagh JJ (2003) Anticancer therapy targeting the apoptotic pathway. Lancet Oncol 4(12):721-729. https://doi.org/10.1016/ S1470-2045(03)01277-4

Ji S, Lin W, Wang L, Ni Z, Jin F, Zha X, Fei G (2017) Combined targeting of mTOR and Akt using rapamycin and MK-2206 in the treatment of tuberous sclerosis complex. J Cancer 8(4):555-562. https://doi. org $/ 10.7150 / \mathrm{jca} .17205$

Kiessling MK, Curioni-Fontecedro A, Samaras P, Lang S, Scharl M, Aguzzi A, Oldrige DA, Maris JM, Rogleret G (2016) Targeting the mTOR complex by Everolimus in NRAS mutant neuroblastoma. PLoS ONE 11(1):e0147682. https://doi.org/10.1371/journal.pone. 0147682

Kim K, Kong S-Y, Fulciniti M, Li X, Song W, Nahar S, Burger P, Rumizen MJ, Podar K, Chauhan D, Hideshima T, Munshi NC, Richardson P, Clark A, Ogden J, Goutopoulos A, Rastelli L, Anderson KC, Tai YT (2010) Blockade of the MEK/ERK signaling cascade by AS703026, a novel selective MEK1/2 inhibitor, induces pleiotropic anti-myeloma activity in vitro and in vivo. Br J Haematol 149(4):537-549. https://doi.org/10.1111/j.1365-2141.2010.08127.x

Kim JO, Kim KH, Song IS, Cheon KS, Kim OH, Lee SC, Lee SK, Kim SJ (2017) Potentiation of the anticancer effects of everolimus using a dual mTORC1/2 inhibitor in hepatocellular carcinoma cells. Oncotarget 8(2):2936-2948

Konopleva M, Contractor R, Tsao T, Samudio I, Ruvolo PP, Kitada S, Deng X, Zhai D, Shi YX, Sneed T, Verhaegen M, Soengas M, Ruvolo VR, McQueen T, Schober WD, Watt JC, Jiffar T, Ling X, Marini FC, Harris D, Dietrich M, Estrov Z, McCubrey J, May WS, Reed JC, Andreeff M (2006) Mechanisms of apoptosis sensitivity and resistance to the BH3 mimetic ABT-737 in acute myeloid leukemia. Cancer Cell 10(5):375-388. https://doi.org/10.1016/j.ccr. 2006.10.006

Li X, Dai D, Chen B, Tang H, Xie X, Wei W (2018) Efficacy of PI3K/AKT/mTOR pathway inhibitors for the treatment of advanced solid cancers: a literature-based meta-analysis of 46 randomised control trials. PLoS One 13(2):e0192464. https://doi.org/10.1371/ journal.pone. 0192464

Lin T, Leung C, Nguyen KT, Figlin RA (2016) Mammalian target of rapamycin (mTOR) inhibitors in solid tumors. Clin Pharm 8. https://doi.org/10.1211/CP.2016.20200813

Lu JW, Lin YM, Lai YL, Chen CY, Hu CY, Tien HF, Ou DL, Lin LI (2015) MK-2206 induces apoptosis of AML cells and enhances the cytotoxicity of cytarabine. Med Oncol 32(7):206. https://doi.org/10. 1007/s12032-015-0650-7

Lui A, New J, Ogony J, Thomas S, Lewis-Wambi J (2016) Everolimus downregulates estrogen receptor and induces autophagy in aromatase inhibitor-resistant breast cancer cells. BMC Cancer 16(16):487. https://doi.org/10.1186/s12885-016-2490-Z

Milella M, Falcone I, Conciatori F, Matteoni S, Sacconi A, de Luca T, Bazzichetto C, Corbo V, Simbolo M, Sperduti I, Benfante A, del Curatolo A, Cesta Incani U, Malusa F, Eramo A, Sette G, Scarpa A, Konopleva M, Andreeff M, McCubrey JA, Blandino G, Todaro M, Stassi G, de Maria R, Cognetti F, del Bufalo D, Ciuffreda L (2017) PTEN status is a crucial determinant of the functional outcome of combined MEK and mTOR inhibition in cancer. Sci Rep 7:43013. https://doi.org/10.1038/srep43013

Milinkovic M, Sprung M, Buljubašić M, Novak I (2018) Autophagy modulation in cancer: current knowledge on action and therapy. 
Oxidative Med Cell Longev Article ID 8023821, 18 pages. https:// doi.org/10.1155/2018/8023821

Mowers EE, Sharifi MN, Macleod KF (2017) Autophagy in cancer metastasis. Oncogene. 36:1619-1630

Neufeld TP (2012) Autophagy and cell growth - the yin and yang of nutrient responses. J Cell Sci 125(10):2359-2368. https://doi.org/ $10.1242 /$ jcs. 103333

Nikoletopoulou V, Markaki M, Palikaras K, Tavernarakis N (2013) Crosstalk between apoptosis, necrosis and autophagy. Biochim Biophys Acta 1833(12):3448-3459. https://doi.org/10.1016/j. bbamcr.2013.06.001

Paquette M, EI-Houjeiri L, Pause A (2018) mTOR pathways in Cancer and autophagy. Cancers (Basel) 10(1):18. https://doi.org/10.3390/ cancers 10010018

Park SJ, Hong SW, Moon JH, Jin DH, Kim JS, Lee CK, Kim KP, Hong YS, Choi EK, Lee JS, Lee JL, Kim TW (2013) The MEK1/2 inhibitor AS703026 circumvents resistance to the BRAF inhibitor PLX4032 in human malignant melanoma cells. Am J Med Sci 346(6):494-498. https://doi.org/10.1097/MAJ.0b013e318298a185

Peng T, Dou P (2017) Everolimus inhibits growth of gemcitabineresistant pancreatic cancer cells via induction of caspase-dependent apoptosis and G2/M arrest. J Cell Biochem 118:2722-2730. https:// doi.org/10.1002/jcb.25921

Pfeffer CM, Singh ATK (2018) Apoptosis: a target for anticancer therapy. Int J Mol Sci 19(2). https://doi.org/10.3390/ijms19020448

Ruzzolini J, Peppicelli S, Andreucci E, Bianchini F, Margheri F, Laurenzana A, Fibbi G, Pimpinelli N, Calorini L (2017) Everolimus selectively targets vemurafenib resistant BRAFV600E melanoma cells adapted to low $\mathrm{pH}$. Cancer Lett 408(1):43-54

Sathe A, Nawroth R (2018) Targeting the PI3K/AKT/mTOR pathway in bladder Cancer. Methods Mol Biol 1655:335-350
Sathe A, Chalaud G, Oppolzer I, Wong KY, Busch M, Schmid SC, Tong Z, Retz M, Gschwend JE, Schulz WA, Nawroth R (2018) Parallel PI3K, AKT and mTOR inhibition is required to control feedback loops that limit tumor therapy. PLoS ONE 3(1):e0190854. https:// doi.org/10.1371/journal.pone.0190854

Watanabe R, Wei L, Huang J (2011) mTOR signaling, function, novel inhibitors, and therapeutic targets. J Nucl Med 52(4):497-500

Weeber F, Cirkel GA, Hoogstraat M, Bins S, Hooijdonk C, Ooft S, Werkhoven E, Willems SM, Stralen M, Veldhuis WB, Besselink NJM, Horlings HM, Steeghs N, Jonge MJ, Langenberg MHG, Wessels LFA, Cuppen EP, Schellens JH, Sleijfer S, Lolkema MP, Voest EE (2017) Predicting clinical benefit from everolimus in patients with advanced solid tumors, the CPCT-03 study. Oncotarget 8(33):55582-55592

Woo SU, Sangai T, Akcakanat A, Chen H, Wei C, Meric-Bernstam F (2017) Vertical inhibition of the PI3K/Akt/mTOR pathway is synergistic in breast cancer. Oncogenesis 6(10):e385. https://doi.org/10. 1038/oncsis.2017.86

Xiang R-F, Wang Y, Zhang N, Xu W-B, Cao Y, Tong J, Li J, Wu Y-L, Yan $H$ (2017) MK2206 enhances the cytocidal effects of bufalin in multiple myeloma by inhibiting the AKT/mTOR pathway. Cell Death Dis 8:e2776. https://doi.org/10.1038/cddis.2017.188

Yang F, Gao J-Y, Chen H, Du Z-H, Zhang X-Q, Gao W (2017) Targeted inhibition of the phosphoinositide 3-kinase impairs cell proliferation, survival, and invasion in colon cancer. OncoTargets Ther 10: 4413-4422. https://doi.org/10.2147/OTT.S145601

Zeng Y, Tian X, Wang Q, He W, Fan J, Gou X (2018) Attenuation of everolimus-induced cytotoxicity by a protective autophagic pathway involving ERK activation in renal cell carcinoma cells. Drug Des Devel Ther 12:911-920. https://doi.org/10.2147/DDDT. S160557 